lymph glands participate in this function. He froquently found eosinophilic myelocytes in them but very rarely normoblasts. When we turn to anæmias we find less written about the spleen and lymph glands. Wolff ${ }^{6}$ found in a case of anrmia due to chronic lead poisoning that the bone marrow was defective in the production of neutrophils, but that the spleen, although not enlarged, was producing them freely. Hirschfeld ${ }^{7}$ quotes Rindfleisch as baving, in 1881 , found normoblasts in the lymph glands of a child with anæmia and marked rickets. Fowler ${ }^{8}$ and Melland, ${ }^{8}$ discussing splenic anæmia of infants, have very little to say about the histology of the condition, with the exception that Fowler found eosinophilia of the spleen in two cases. R. Hutchison ${ }^{10}$ in his Goulstonian lectures for 1904 reviewed the reports of the histological findings recorded by various observers. From these reports it appears that we can as yet postulate no definite morbid anatomy and histology for the condition. He quotes, however, Luzet, Mya and 'Irambusti, and Hunt as having, in their cases, found the liver to be foetal as in our case. Fowler ${ }^{11}$ mentions jaundice as occurring in three cases, twice transient and once associated with acute hepatitis. We can offer no satisfactory explanation of it in this case. The results of the blood examination were not abnormal for infantile splenic anæmia, and accord well with those given by Fowler. Melland, and Hutchison, except that the count of erythroblasts was very high, 7500 normoblasts and 400 megaloblasts per cubic millimetre. Melland mentions one case with 9353 erythroblasts.

As to the production of the anæmia our investigations give us no clue. The phagocytosis of erythrocytes in the lymph glands was not a very marked feature, while we have seen none of that in the spleen, as opposed to the findings of Harris and Herzog ${ }^{12}$ in splenic anæmia of adults. If there had been no blood examination the histology of the blood-forming organs would have suggested myelæmia but the blood examination negatives that supposition. Of course, it is a priori possible to say that the child may have died in the pre-leukæmic stage of myelamia, or that the bloor picture of myeliemia was altered by an infection; but the former proposition is susceptible of neither proof nor disproof, while there is no evidence in favour of the latter. Also myelromia is very rare in children. Infantile splenic anæmia is common enough clinically; many cases thus classified are really examples of anæmia due to rickets or congenital syphilis, but in this case there was no evidence of either. On the other hand, they do not frequently come to the post-mortem room. and as their pathology is obscure we have thought the case worth publishing. The chief importance of it, however, lies in the fact that it shows that under suitable stimulation the indifferent lymphoid cells of the lymph glands can evolve exactly as they do normally in the red bone marrow.

\section{RAPID GENERAL MYASTHENIA GRAVIS.}

BY H. WORK DODD, F.R.C.S. ENG., lte, OPITTHALMIC SLRGEUY I'U, AXYD CLINICAL IICCTIRFR ON OPHTHALMIC MEDICIXE AYD SURGERY AT, THE ROYAL FREE FOSPITAL

$$
\text { A YND }
$$

\section{A. STANLEY WOODWARK, M.R.C.S. ExG.,} L.R.C.P. LOND.,

SEYIOR RESIDEX'T YEDICAL OFFICER, ROYAL FREE HOSPITAL.

As so little is known of this interesting condition it is well to record the notes of every case.

The patient, married, aged 25 years, a copying clerk, was admitted into the Royal Free Hospital on Nov. 10th com. plaining of weakness. The history of the illness dated back only six weeks. Previously the patient had always been a healthy man and, in fact, was playing football two days before the "feveri-h attack" about to be described. About the beginning of October he had "influenza" with bad pains in his back and legs, running from his nose and eyes, and

6 Ibid., No. 36, and Brit. Med. Jour., Epitome, Feb. 7th, 1903. T Loc cit. Loc. cit. Brit. Med, Jour.,

10 The LanceT, Mav 7th, 1904, p. 1253.

12 Annals of Surgery, July, 1901. feverishness. The attack lasted for abont a week but did not stop the patient from continuing at his work. After this he felt weak and four weeks ago noticed a slight difficulty in chewing his food. His jaw muscles seemed to get tired after he had partaken of a few mouthfuls. At about the same time he noticed weakness of the right leg and a few days later difficulty in holding up his head while at work. When tired his head used to droop till his chin touched his chest. His shoulders ached constantly and he could with difficulty hold himself erect. Walking fatigued him quickly. Within the last two weeks the patient had noticed dropping of his eyelids, the left eye being affected first. Since then he had not been able to open his eyes fully, this condition progressing during the day till towards evening he could barely hold them open. As night approached he had diffculty in taking liquid food and said that it had occasionally returned through his nose. Subsequently he noticed weakness in the hands. Two days before admission he suddenly became so much weaker that he fell down once or twice and eventually had to lie down. There was no history of syphilis, alcohol, or pulmonary tuberculosis. 'There was nothing in the family history bearing on the case. When first seen the patient was very pale and rather thin. The face had a listless, apathetic, mask-like expression. The jaw was generally slightly dropped. There was marked and constant ptosis of the left eye and occasionally less marked ptosis of the right eye. The lower lids always showed two or three millimetres of sclerotic below the corneæ. The quality of the voice appeared to be unaltered. The lips and mucous membrancs were rather pale. There were no enlarged glands and his skin was quite normal. 'There were no developmental defects of the hands or feet.

An examination of the various systems showed the following phenomena:- There were no deformity and no tender area in the skull. The superciliary ridges were extremely prominent. This, with a somewhat prominent lower jaw, gave the face something of an acromegalic appearance. The spinal column showed nothing abnormal. The patient could walk, performing the movements correctly but very weakly and soon got tired. When in bed he could only raise himself with difficulty to the sitting posture. If he read aloud his eyes, jaws, and hands soon became fatigued in the order mentioned, so that his eyelids drooped, be had to support his lower jaw with his hand, and finally allowed the book to fall.

There were no fibrillary tremors of the muscles. An examination of the individual muscles showed that on both sicles the triceps, deltoid, and pectorals were very weak and the supinator longus and biceps fairly good; the intercostals acted well, erector spinæ, trapezius, and infraspinatus weakly, while the rhomboids were fairly strong. The grip on both sides was extremely feeble. In the legs no definite paralysis of the posterior or anterior tibial groups was noticed but both were slightly affected, so that they were not as strong as the quadriceps extensor. The adductors were weak. All the muscles reacted well to faradism but as the examination proceeded the contractions became intermittent and finally ceased. This phenomenon was best seen in the muscles markedly paretic but was present also to some extent generally. The reaction to galvanism was normal. Coördination and sensation were unaffected. On testing the reflexes the plantar response was found to be flexor in character and occasionally absent altogether. The knee-jerks were exaggerated but decreased gradually if the attempts to elicit them were persisted in. Ankle clonus was present sometimes. The supinator longus and the palate reflexes were present. Jaw clonus was marked. The lumbar centres were unaffected. There was no loss of control over the acts of defacation and micturition.

The cranial nerves are best considered seriatim. I. Olfactory normal. II. Optic dises normal. The vision and visual fields were normal. There was no alteration of colour vision and no scotomata were to be found. III., IV., and VI. There were marked ptosis, no squint, and no nystagmus in any position of the eyes. Diplopia was occasionally complained of. The movements of the eyeballs were incomplete, the downward movement being better than that in any other direction. The pupils' were about four millimetres in diameter and equal. They reacted to light, accommodation, and convergence. As convergence was imperfect the patient could read better with one eye at a time than with botlı. V. Sensation over his face was unaffected. The muscles of mastication acted feebly and soon became fatigued. VII. The occipito-frontalis musele acted pretty well. The 
;orbicularis palpebrarum was very weak. The patient copld pot firmly. shut his eyelids but could only just close them and offered no resistance to attempts at opening them. There was a certain degree of absence and incompleteness of nictitation. The orbicularis oris was very weak. He could not whistle or show his teeth. When he laughed his face assumed a sneering expression owing to the fact that he only raised his upper lip so that the nasolabial furrow did not extend round the corners of the mouth. VIII. Unaffected. IX. Taste unaffected. $X$. and XI. The patient had no difficulty in swallowing whilst an in-patient although he gave a previous history of that condition. The muscles supplied by the eleventh were, as stated above, weak. XII. He could only protrude the tongue incompletely. There were no fibrillary tremors.

The respiratory and circulatory systems were normal. A blood count showed 5,300,000 red corpuscles and 9600 white corpuscles per cubic millimetre. The pulse was generally about 80 and the respirations were 18 per minute.

The urinary system was normal; the urine was alkaline, turbid from urates, and contained neither albumin nor sugar. The digestive system was normal and the liver and spleen did not appear to be enlarged. His temperature remained normal or rather subnormal. He lost three and a half pounds in weight during the ten days he was in bospital and left with his condition unimproved. He was treated with the usual tonics, iron, arsenic, and strychnine.

It was a most markedly typical case of myasthenia gravis and showed such a rapid progress that in four weeks from a strong healthy man the patient became so extremely weak that he actually fell and later could not raise himself in bed. The onset of the trouble appeared to have followed an attack of influenza and it is possible that this disease may stand in a causal relation to this case. He appeared to have such a difficulty in feeding himself before he came into the hospital that he felt half starved and this may have added somewhat to his rapid increase in weakness. His mental condition was remarkably good and acute; there were a certain depression of spirits and a tendency perhaps to suspicion. Since leaving the hospital he has been under the care of Dr. T. Battersby Jobson of Ilford, who reports on April 11th, 1905 , that "he was little better than he was on leaving the hospital."

\section{A SIMPLE TECHNIQUE FOR THE ENUME- RATION OF ORGANISHS IN ANY FLUID.}

BY W. H. C. FORSTER, M.B., C.M.EDIN., D.P.H.CANTAB., CAPTAIN, I.M.S.

(From the Laboratory of the Pasteur Institute of India, Kasauli.)

CRITICAL consideration of the plating-out method of estimating the number of organisms in fluids such as water, milk, sewage, \&c., reveals several disadvantages apart from the inaccuracies inseparable from the method. The two chief disadvantages are the multiplicity of manipulations and the quantity of apparatus required, the result being that in routine work the amount of time expended on the process is altogether out of proportion to the value of the information obtained. It will be readily admitted that in actual practice information as to the source of the sample will often indicate the probable number of contained organisms sufficiently well to save the experienced investigator from much unnecessary manipulation; but, on the other hand, cases not infrequently occur in which such information is either not available or if available will not suffice to guide the investigator in the important question as to the limit dilution to be employed. For example, I have received within a fortnight three samples of stored rain water which contained respectively 100,1600, and 3,000,000 organisms per cubic centimetre. On the basis of these results a rigid application of the method of plating out, as recommended by the committee of experts appointed by the Royal Institute of Public Health, ${ }^{1}$ to future samples of stored rain water would necessitate an expenditure of time and energy which could be more profitably employed in other

1 Journal of State Medicinc, Angust, 1904. directions. I would submit that for routine work it will be sufficient if in place of the actual number of organisms per cubic centimetre we can state reasonable limits, such as $10-100,100-1000,1000-10,000,10,000-100,000$, \&c., within which the actual number of organisms must lie and therefore any method of enumeration which fulfils this requirement and in addition offers considerable advantages over the plating-out method in respect to the number of manipulations and quantity of apparatus required is worthy of consideration on the part of the general body of laboratory workers on public health questions. If a method can be devised which will go further and in addition to the above advantages will indicate with an accuracy equal to, if not greater than that of, the plating.out method the total number of organisms per cubic centimetre in terms of 10 $100,1000,10,000,100,000$, \&c., then a very strong case can be made out in its favour in opposition to the plating-out method as at present practised. I have therefore felt justified in putting before my fellow workers a method of enumerating organisms in any fluid which I have used in routine work for some months past and which seems to me to fulfil the following requirements: (1) Minimum number of manipulations; (2) minimum quantity of apparatus; and (3) accurate estimation of the total number of organisms in terms of 10, 100, 1000, $10,000, \& c$.

'The method in question is not original, being merely a modification of the technique introduced by my former teacher Dr. A. E. Wright for the estimation of the number of living organisms in a given culture and used by him in connexion with his researches on the blood serum. The technique referred to is described in detail by Dr. Wright in his original papers, to which the reader is referred, ${ }^{2}$ but in order to give an intelligible description of the modification I have adopted it will be necessary for me to repeat some of the subject-matter of those papers. The method is applicable to the quantitative estimation of bacillus coli, streptococcus, and the spores of bacillus enteritidis sporogenes in sewage effluents in addition to the quantitative estimation of organisms in water, milk, \&c., but it will be sufficient for the purposes of description to state the details of the method as applied to the quantitative estimation of organisms in water.

\section{DESCRIPTION OF THE METHOD.}

The following is the apparatus required: three sterile diluting pipettes; three sterile watch glasses; eight agar slopes numbered from 1 to 8 consecutively; eight gelatin slopes numbered from 1 to 8 consecutively; and a vessel containing sterile water. The pipette which 1 use and which I have found to be extremely useful as a general service instrument in the laboratory is graduated differently from Dr. Wright's original model. The stem of the pipette is graduated in ten divisions of five cubic millimetres each, the remaining graduation marks indicating 450 cubic millimetres and 500 cubic millimetres respectively. The safety chamber is dispensed with, the shank of the pipette being merely bent to a right angle in the blow-pipe flame. With the exception of these differences the pipette is constructed and graduated according to the directions of Dr. Wright.

The steps of the operation are as follows. 495 cubic millimetres of sterile water are measured into each watch glass. This quantity is obtained by filling the pipette up to the 500 cubic millimetre mark and withholding five cubic millimetres when injecting into the watch glass. From the water to be examined five cubic millimetres are removed with the pipette-care being taken not to soil the pipette above the five cubic millimetre mark -and added to the contents of the first watch glass. This gives a dilution of 1 in 100 . The contents of the watch glass are then thoroughly mixed with the pipette and from this dilution 100 cubic millimetres (ottined by filling twice up to the 50 cubic millimerre mark, interspacing with an air bubble) are planted out in t'se gelatin and agar tubes numbered 3. Similarly, 10 cubic millimetres are planted out in the tubes numbered 4. From the 1 in 100 dilution five cubic millimetres are then transferred to the second watch glass, giving a dilution of 1 in 10,000 . With the same pipette 100 cubic millimetres and ten cubic millimetres of the original water are planted out in the tubes numbered 1 and 2 respectivelr. (This manceuvre requires a little explanation. If, instear if proceeding as described, tubes 1 and 2 were first seeded and then five cubic millimetres of the original water were added

2 Proceedings of the Royal Societ5, 1902 ; THE LAXCET, June 1st, 1901, p. 1532 